\title{
Diálogos sobre a dimensão subjetiva em tempos da pandemia do coronavírus
}

\section{- Dialogues on the subjective dimension in times of the coronavirus pandemic}

Resumo: O coronavírus (Covid-19) chegou e instalou uma pandemia mundial, como um redemoinho revirando a vida das pessoas, das instituições e dos países, sem componente ideológico, condição econômica e discriminação social. Como uma resposta de séculos de domínio da ciência sobre a natureza, junto com a pandemia, a Amazônia e o Pantanal choram o extermínio dos animais e das florestas, como expressão da violência contra a Mãe Terra. O filho do homem e as matas chegam ao limite, denunciando o quanto a lógica do lucro destrói a terra e seus habitantes. Como uma pandemia afeta mentes e corações? Como o choque da pandemia do Coronavírus alerta de forma crítica os nossos modos civilizatórios de produzir o conhecimento e agir sobre a natureza construindo cultura? O texto pretende levantar pontos de reflexão em que a vida em pandemia afeta nosso dia a dia, nossos sentimentos, atitudes, modos de ser e agir, como pontos de interseção entre a psicologia e a sociedade, tendo como parâmetro ético e politico, a educação em direitos humanos.

Palavras-chave: Covid-19. Direitos humanos. Subjetividade.

Abstract: The coronavirus (Covid-19) arrived and installed a worldwide pandemic, like a whirlwind overturning the lives of people, institutions and countries, without an ideological component, economic condition and social dis-

1 Psicóloga Social, professora do Departamento de Serviço Social, do Programa de Pós-Graduação em Direitos Humanos, Cidadania e Politicas Públicas e do Programa de Pós-Graduação em Educação da UFPB. 
crimination. As a response of centuries of dominance of science over nature, together with the pandemic, the Amazon and the Pantanal mourn the extermination of animals and forests, as an expression of violence against Mother Earth. The son of man and the woods reach the limit, denouncing how much the logic of profit destroys the land and its inhabitants. How does a pandemic affect minds and hearts? How does the shock of the Coronavirus pandemic critically alert our civilizing ways of producing knowledge and acting on nature building culture? The text aims to raise points of reflection in which life in a pandemic affects our daily lives, our feelings, attitudes, ways of being and acting, as points of intersection between psychology and society, having as an ethical and political parameter, education in human rights.

Keywords: Covid-19. Human rights. Subjectivity.

\section{Introdução}

A ciência de abordagem positivista adota uma relação de distanciamento entre investigador e o objeto de estudo como uma perspectiva do fazer ciência. Tal linha teórica vem fundamentando um modo de enxergar a natureza, assim como o modo de agir através de um instrumental que pode desdobrar-se na produção de conhecimentos uteis da vida humana. Ao defrontar-se com os fenômenos sociais - que são complexos e multidimensionais - tal abordagem entra em dissonância com o mundo das ciências humanas sociais que exigem processos complexos de captação, investigação e análise.

O paradigma positivista quando tenta enquadrar os fenômenos sociais, pretendendo uma formação científica "neutra" como se a ciência não tivesse relação com a realidade material e histórica e as relações de poder presentes na sociedade, retira o componente da tensão presente na energia que permeia a vida dos astros.

Ao tentar alcançar a tal pretendida neutralidade científica, a "formação" de psicólogos se revestiu com capas de proteção, encerrando os futuros profissionais em laboratórios com lentes de baixa visibilidade. Sem articular a pesquisa com a experiência extencionista, continua-se a correr risco de não oferecer uma formação verdadeiramente científica e contextualmente implicada. Nesse sentido, uma parte da Psicologia passou longos anos separados do saber da Antropologia, da Sociologia e da Filosofia tentando reduzir os fenômenos psicológicos ao observável e quantificável, transformando o comportamento humano em números, escalas e gráficos. Psicólogos foram transformados em leitores de dados estatísticos, distanciando-se da realidade dos sujeitos. 
A tal chamada neutralidade cientifica além de segmentar o objeto de investigação distanciou o profissional de distintas razões que contribuem para explicar os fenômenos humanos. Com isso, correntes teóricas da Psicologia foram se distanciando da complexidade e ao mesmo tempo se descompromissando com os problemas cotidianos da sociedade.

Enquanto parte significativa da Psicologia estivesse sendo treinada para ler tabelas e gráficos em laboratórios, ou mesmo, aplicando testes para quantificar o comportamento humano, outra parte da Psicologia arriscava-se a critica buscando no diálogo com as ciências humanas e da sociedade o entendimento dos fenômenos subjetivos.

Distantes do mundo real e isolados em laboratórios e salas hermeneuticamente fechadas, uma parte da Psicologia defrontou-se com uma encruzilhada: para que a Psicologia? Qual a função social da universidade? Como a Psicologia pode contribuir para ler e entender a condição humana em sociedades complexas e desiguais ao ponto de encontrar pontos de fugas que levem a valorizar a vida e a pessoa como sujeito de dignidade e subjetividade? Como entender os fenômenos inconscientes, o sofrimento psíquico, a subjetividade e o comportamento humano sem contextualizar a pessoa a cultura e a realidade?

Entretanto, quando parte da Psicologia se aproxima do Brasil real, ela compreende que há muito a pesquisar para compreender a dimensão da história e a dinâmica da sociedade, de modo a contribuir para a produção de indivíduos e grupos sociais capazes de realizar o mais idealmente possível a condição humana. A partir deste momento, através da extensão universitária, os estudantes da Psicologia vão até aldeias, assentamentos rurais, comunidades quilombolas, territórios de ciganos, hospitais psiquiátricos, unidades do SUS (Sistema Único de Saúde) e do SUAS (Sistema Único de Assistência Social) e se defrontam com um monstro desconhecido, o ser humano com suas dimensões da subjetividade, atitude e comportamentos.

Em tempos de dissolução das certezas de preservação da vida, como os tempos atuais, nos questionamos: por que razão foi preciso uma pandemia para fazer o mundo enxergar o mal estar civilizatório? Como o contexto de pandemia tem mobilizado os saberes psicológicos como ferramenta de alívio do sofrimento humano através da rede virtual?

Em situação de pandemia a dimensão da subjetividade tem vindo à tona pela necessidade humana de preservar a vida biológica e a vida psíquica. Viver aldeado, em celas, em palafitas, em barracos de papelão e flandres parecia algo distante de parte dos demais humanos. De repente, uma pandemia coloca todos os seres humanos sem distinção em situação de desamparo social, e ai o homem percebe que ou todos tem vida ou ninguém terá vida.

Diante de um isolamento forçado muitos colocam a necessidade ma- 
terial e social à frente da vida e topam desafiar a pandemia entrando em ônibus superlotados para garantir o emprego. Outros encantados com o brilho do lucro, mobilizam-se em manifestações e carreatas para pressionar os dirigentes a reduzirem as medidas de confinamento social. Com mais de 110.000 brasileiros mortos pela pandemia de Covid-19 o país abre o comércio e os serviços para que a economia sobreponha-se a vida humana. Trata-se de uma família de vírus que tem causado infecções em órgãos vitais e levado a humanidade a paralisar todas as atividades econômicas para evitar o contagio e a mortalidade em massa.

Enquanto isso se altera a legislação do meio ambiente e se perde significativa área verde em nome do lucro das madeireiras, mineradoras e fazendas de gado. A terra devassada pela destruição enlouquecida do meio ambiente avisa que só com os povos originários poderemos recompor e proteger a Amazônia, porque eles entendem que a vida humana depende da natureza, diferente de uma perspectiva de ciência que o conhecimento servia para dominar a natureza e os homens ao invés de libertá-los. Qual será o futuro da humanidade sem a sobrevivência dos caciques e povos indígenas que protegem a floresta?

O presente artigo tem por objetivo participar dos diálogos sobre a dignidade humana em tempos de pandemia a convite da Revista Interdisciplinar de Educação em Direitos Humanos - UNESP-Bauru, trazendo contribuições da Psicologia Social e da educação em direitos humanos numa perspectiva crítica para refletir o tempo presente.

\section{Uma pandemia sem limite}

A sociedade de consumo focada na produção material e da riqueza tratando o ser humano no sentido restrito como força de trabalho, tem construído espaços de sociabilidade onde o sentimento de pertencimento tem se fragilizado em face do padrão individualista gestado numa economia do mercado.

Nessa lógica, estávamos todos atarefados na luta pela sobrevivência, muitas vezes sem tempo para ouvir os filhos, encontrar os amigos e cuidar de si e conviver com os demais, quando a pandemia chegou e parou a máquina. No inicio não entendíamos nada, sentíamos confusos e aflitos sem saber qual o número seria o que traduziria a nossa vida nas taxas de mortalidade pelo Coronavírus. A cada boletim a angustia nos mobilizava e nos fazia parar em casa.

A pandemia tem sido um custo altíssimo para toda a humanidade. Do empresário, ao banqueiro e ao peão, do presidente ao mendigo e ao profissional da saúde, a vida tem o mesmo valor para todos. Ou cuidamos todos de todos ou padeceremos já que a pandemia prova que a saúde de um depende da saúde de todos.

As crianças pedem pelo amor de Deus: fiquem em casa; enquanto par- 
te de comerciantes e industriais enchem as ruas de carros importados exigindo a volta ao trabalho, nem que para isso, os trabalhadores arrisquem sua vida enquanto os patrões ficam em casa protegidos. Não importa quantos dias o trabalhador, o enfermeiro, o médico terão de vida, se faltam equipamentos de segurança ou mesmo se faltam hospitais estruturados em todas as unidades da federação, garantindo a todos o direito à vida.

Como se não houvesse meios de regulação, alguns aproveitam-se do momento pandêmico para cometerem crimes de corrupção com recursos da saúde. Outros, lavam as mãos com o número alto de mortalidade como se não respondessem por crimes de responsabilidade no exercício da função pública. Quantas mortes precisarão ocorrer para que a saúde seja prioridade sobre a politica econômica?

From (1970) alerta, a liberdade material e a econômica podem estarem permeadas de solidão e alienação, já que a cultura do consumo é solitária. A pandemia também ensina, quando ironicamente exige o isolamento como condição para preservar a vida humana. Em tempos de isolamento, novos modos de ser são despertados, alguns voltam a brincar, cozinhar, bordar, ler, cantar, fazer yoga e até inventar treinamentos físicos em casa. Mas o isolamento também exalta outras violências, aumentando a necessidade de medidas de proteção de mulheres e crianças vitimas de violência domestica.

A dor não é mais um requisito de sensibilidade diante da morte previsível a todos? A dor da perda de entes familiares não limita governantes e empresários?

A pandemia ensina, ou se cuida dos serviços de saúde como política pública e universal ou estaremos todos convivendo com ondas de pandemias e destruição, pois a Terra chegou ao limite. Os animais do pantanal gritam quando sobrevivem ao fogo. Os animais invadem as cidades para fugir da seca, do fogo e da morte.

Não se trata mais, de pedir esmolas a governos sensíveis à causa social para reduzir a extrema pobreza, não tem como mais acusar a periferia da desgraça dos problemas de saúde. Ou todos têm saúde ou a pandemia chegará a todos. A pandemia inclusive acordou a sociedade de que nos territórios de exclusão nem sabão e nem água o cidadão tem acesso. As mídias alternativas têm escancarado retratos das desigualdades sociais que pareciam invisíveis nas estatísticas dos planejadores públicos.

\section{Pandemia, Estado e saúde pública}

Quando o Estado de mal estar civilizatório sobrepõe o de bem estar, o ser humano passa a se concentrar na morte em vez da vida. Para uns, o papel do Estado se restringe a contar quantos cidadãos foram acometidos da pan- 
demia ou quantos morreram e divulgar como uma sessão de esporte. Para outros, o papel do Estado é rever a direção das políticas públicas de modo a mudar as prioridades, já que, quem administra o poder público, manuseia os recursos coletivos. O desemprego que já fazia parte do cotidiano da vida de uma parcela significativa de brasileiros passou a exigir, em tempos de pandemia, que o poder público mobilize recursos para oferecer socorro emergencial, pois querendo ou não dos economistas vão ter que liberar os recursos da proteção social.

Uma postura republicana presta conta dos serviços com transparência, priorizando medidas de preservação da vida através de campanhas como: Fique em casa, não é uma gripe comum. Mudem e inventem uma nova forma de vida em casa. Até os meios de comunicação estão mudando sua forma de fazer a comunicação.

Já os governadores do Nordeste antes da pandemia estavam enfrentando a redução de recursos para área social, de saúde e educação. Com a pandemia se juntaram em rede para proteger a vida, construir e reformar hospitais, decretar o isolamento e o uso obrigatório e maciço de máscaras como barreira ao vírus, dentre outras medidas criando um comitê gestor conjuntamente.

O gestor responsável não dorme, pois há necessidades emergenciais a serem resolvidas para se evitar a destruição da vida de muitos cidadãos. Diálogos diários com a população pela mídia chamam a atenção para necessidade de alcançar os $70 \%$ de isolamento já que não há leitos e nem cemitérios para os que são afetados pelo coronavírus. Os leitos encontram-se 100\% ocupados. Pessoas são atendidas em áreas improvisadas fora dos hospitais por não haver mais leitos, não há equipamentos de saúde para todos, especialmente, para os índios e os ribeirinhos do Norte e Nordeste.

O SUS mostrou sua cara, sem ele não tem como o Estado ter resposta a pandemia. Jaquetas do SUS estão nos corpos dos profissionais da saúde como símbolo de uma conquista coletiva. O desmonte do SUS reflete nas taxas de mortes, assim como nas taxas de sobreviventes. Como cuidar e criar uma rede para proteger os profissionais que todos os dias colocam suas vidas em defesa da vida? É desesperador ouvir o grito do motorista do SAMU gritando se não tem vaga para que o SAMU?

Enquanto isso há gestores públicos que não possuem valores éticos republicanos e democráticos, já que ousam afirmar de que usar dinheiro público para a compra de equipamentos respiratórios é um gasto desnecessário, já que muitos vão morrer, enquanto só o crescimento econômico é capaz de investir na proteção da vida com a pandemia. Quantas vezes o Brasil não socorreu os bancos privados, ou mesmo, quantos bancos públicos não foram fechados para atender aos interesses do FMI, fragilizando o Estado e suas unidades federadas a terem autonomia no processo de crescimento e desenvolvimento social? 
Prestar informação a sociedade de forma ampla pelos meios de comunicação é dever de quem foi escolhido pelo voto direto para governar os recursos públicos. Os meios de comunicação se unem para formar uma rede de informação sobre o coronavírus afim de manter a sociedade informada.

Os partidos de oposição exigem atuação rigorosa dos órgãos de fiscalização para monitorar a aplicação de recursos públicos para todas as unidades da federação, uma vez que alguns estados encontram-se em situação de calamidade pública.

Sem um sistema de saúde pública estruturado a pandemia substituiu as guerras em concorrência do numero de mortes.

Causa mal estar assistirmos diariamente as pessoas no limite extremo da cidadania correr o risco de ser contaminado pelo coronavírus para esmolar R\$ 600,00 reais de um governo que cortou por 20 anos recursos para saúde, educação e assistência social ou que reduziu os recursos do Programa Bolsa Familia para a região nordeste.

Quando pararemos de contar os mortos e enterrá-los em covas coletivas, como em tempos de guerra? Se todos os hospitais estão no limite da sua capacidade de atendimento, para onde o Serviço de Assistência Médica e Urgência vai levar os doentes? Até onde as famílias aguentarão o desespero de chegar com um familiar num hospital e ter como resposta que não há vaga? Como ficar de fora e não ser atendido, deixando a morte chegar? Imaginem o medo e a solidão dos profissionais de segurança, dos profissionais de saúde e dos coveiros convivendo 24 horas com a morte sem a certeza de que garantirão suas vidas e dos familiares?

Cenas diárias nos mobilizam, são profissionais em desespero saindo correndo de um hospital declarando sua demissão em público pela incapacidade humana de aguentar tanto sofrimento diante das mortes diárias.

\section{Pandemia, subjetividade e convivência familiar e social}

A humanidade está vivendo o período mais desafiante da história contemporânea, que é atravessar a pandemia, conhecê-la a fundo e criar mecanismos que possam controlar a destruição da humanidade em massa. Como em Auschwitz, em tempo recorde, volumes de vidas humanas são desfeitas como a poeira no deserto.

A pandemia, como fenômeno social que afeta diferentes coletivos sociais, tem várias dimensões de ser experienciada e representada. Como a Psicologia Social pode refletir a experiência que os sujeitos registram individual e coletivamente com a pandemia? Como esta experiência transforma a subjetividade numa dimensão humana que relaciona sentidos e vivências? 
A dimensão subjetiva atravessa e determina nossas vidas todos os dias. A constituição da subjetividade individual não dissocia a subjetividade dos espaços sociais. Segundo González-Rey (2005, p. 203) os processos de subjetivação em um determinado contexto social [...] "poderá não apresentar repercussões imediatas, mas tende a ser correspondida por reações advindas dos outros integrantes desses espaços, impressas pelos processos de subjetivação característicos desse contexto, gerando assim zonas de tensão".

Diante de uma pandemia pensamentos, sentimentos e emoções têm construídos tensões e sentidos marcados pela situação limite, em que se encontra a humanidade. Muitos se encontram nus, sem direito e proteção social e veem a vida se esvaindo diante de tanta desigualdade e injustiça social.

O enclausuramento como dispositivo de poder foi uma invenção técnico-politica de exclusão territorial e controle social dos pobres, pois os fixando num determinado espaço, seria possível sujeitá-los a uma disciplina (FOUCAULT, 1979).

Entretanto, em uma situação de pandemia, o distanciamento é um dos meios necessários que, de forma consciente, possibilita a comunidade agir na prevenção da contaminação do vírus impedindo que mais pessoas precisem de serviços de emergência que a sociedade não dispõe para socorrer. Com isso, as residências transformaram-se em celas e a cidade em penitenciárias, já que ficar em casa não é uma opção, mas uma condição para evitar a morte e preservar a vida.

Em tempos de pandemia estamos vivendo o distanciamento forçado como forma de defesa da vida, já que outros bens materiais, nesse momento, ficaram em segundo plano. Ter que ficar em casa tem gerado medo, medo da capacidade do Estado de não poder nos proteger, o medo de um colapso social, e o medo de deixar nossos entes queridos, sem mesmo exercer os ritos das despedidas que os seres humanos realizam desde que se sabem humanos. As crianças ensinam: Fique em casa! Defendam a vida. Tirem fotos da varanda, cantem e aprendam a desenvolver a resistência interior. Sejam solidários com os velhos, não neguem a eles o direito à convivência familiar e comunitária, afinal, o que seria das famílias sem os velhos?

A pandemia, para aqueles que desconhecem a força bruta do Estado durante a ditadura militar, demonstra como foi difícil enterrar os filhos com os caixões lacrados para não saber o tipo de tortura sofrida, ou mesmo, entender a dor dos familiares que até hoje não viram os entes mortos, por serem desaparecidos políticos.

Sentimentos, medos e pensamentos atravessam nossa convivência com a pandemia; são as dimensões da nossa subjetividade. O isolamento mobiliza o medo, enquanto a mobilidade deixa a sensação de alívio, quando na verdade, pode se desdobrar, posteriormente, em dor. Nossos medos são reais, 
têm razões e são ameaças vivas na vida das famílias. Não sorrimos em isolamentos por isso os artistas cantam e procuram mobilizar nossos sentimentos e instintos de preservação.

A pandemia nos chama a pensar nossas experiências intersubjetivas diante de uma inevitabilidade maior? Uma rede de escuta surge para fazer com que a violência sentida não destrua o que tem de resistência e capacidade de agir para encontrar saídas. Às crianças ensinam: fique em casa, brinquem, leiam e convivam com os familiares, já que o cotidiano do trabalho e da educação ocupam grande parte do tempo das pessoas.

Não são apenas os loucos e os apenados que estão enclausurados. Os índices de isolamento da quarentena reduzem fazendo os dirigentes ameaçarem de medidas enérgicas, porque sabe que se perderem o controle não terão como sustentar $70 \%$ de isolamento. Enquanto a curva não desce é meta dos dirigentes para que o sistema de saúde não entre em colapso. Flexibilização só com segurança.

Mas como as pessoas confinadas, a sociedade busca fugas para fugir do isolamento, colocando em risco sua vida e dos demais. Por outro lado, nos conectamos na rede virtual com as pessoas significativas da nossa vida, pois não temos a certeza de que as veremos outra vez e possamos nos abraçar novamente, demonstrando todo nosso afeto. Para não sucumbir a esperança todos os dias, escutamos crianças na TV que dizem aos avós que os amam, mas que fiquem distantes para poder não ter o risco de ser contaminado pelo coronavírus. Nesse contexto, filhos de profissionais de saúde - que há mais de 30 dias se encontram distantes dos pais, pois esses estão nas UTIS salvando vidas - mandam abraço aos pais, como se fossem gente grande, encontrando razão para acalmar a dor da saudade. Nesse caminho, avós idosos continuam cuidando dos netos e solidários aos filhos demonstrando que a dignidade não tem idade.

\section{A dignidade humana e os direitos humanos}

A Covid-19 reabre a discussão sobre a dignidade humana quando retrata situações de extrema dor, como o enterro coletivo em valas comunitárias, sem que as famílias possam exercer o direito de despedida de pais e filhos. Estamos aprendendo na dor a resgatar o valor da vida humana.

O medo extremo da morte dos afetados pelo coronavírus nas UTIS espalha-se pela cidade, ao ponto da cidade ter que deixar as luzes acesas com medo das assombrações que a pandemia gera em todos independente da idade e da classe social. Chegamos a uma situação extrema de dor, pois nos encontramos diante de uma situação, em que a vida pode ser dissolvida a qualquer momento se o nosso organismo não for capaz de resistir ao coro- 
navírus, apesar de já termos enfrentado tantas guerras. Mesmo com todo o avanço tecnológico alcançado não conseguimos controlar a pandemia.

A banalidade da vida se expressa nas queimadas da Amazônia ou no descaso com os brasileiros amontoados em filas da Caixa Econômica para acessar $\mathrm{R} \$ 600,00$, ou mesmo, na falta de leitos e hospitais para atender ao público permanente do Estado, uma vez que seus dirigentes e parlamentares legitimam medidas de contenção por 20 anos de recursos para saúde, educação e assistência social. A indiferença de dirigentes em comentar o número de mortes como se fosse contar feijão, afirmando que um número $x$ de mortos será natural, e que todos devem voltar ao trabalho.

A espécie humana chegou a um ponto que precisa redefinir os valores se quer proteger a vida de todos os seres vivos. Quando os entes queridos se vão sem mesmo se despedir, a pessoa para e reflete qual o valor que estamos dando a vida humana. Um projeto de educação para os direitos humanos deve mobilizar o que há de mais sensível no ser humano que é ser capaz de escutar os gritos de dor como se fosse à própria carne, afirma Aguirre (1997).

O que estamos ensinando, que afirmamos a vida e que contribuímos para que as pessoas possam ser capazes de refazer os caminhos de uma autoconsciência? Queixávamo-nos das ações afirmativas porque não queríamos compartimentalizar os recursos públicos com todos os brasileiros, incomodávamo-nos com as pessoas com deficiência na escola e na universidade, reclamávamo-nos com as pessoas de vários segmentos sociais andando de avião e frequentando as instituições públicas, como se fosse possível determinar quem é humano. Todos que sobrevivem ao vírus tentam repassar a experiência pedindo aos que duvidam da pandemia: fiquem em casa! Os profissionais de saúde enfrentam a impotência frente a uma pandemia tão violenta que esmaga a prepotência da ciência, a responsabilidade dos governantes e até a capacidade de resistência humana.

Nem a saúde dos agentes da saúde tem sido prioridade dos dirigentes, haja vista, as denúncias e a mortalidade desse segmento essencial para cuidar da população. Quem cuidará dos doentes sem os agentes de saúde? Por acaso a onipotência do econômico?

Artistas do mundo e grupos se formam mobilizando-se pela África, pelos profissionais da saúde e pelos segmentos economicamente subalternizados. Ações coletivas mobilizam a sociedade, ensinando que na dor entendemos e soletramos a palavra solidariedade (outro sentido dos Direitos Humanos). É nesse processo de sensibilização e racionalidade que exercitamos nossa capacidade de alteridade em escutar gritos de dor, indignar-se e agir em direção à vida. Como afirma Aguirre (1997) é na compaixão que nos identificamos e agimos em direção ao outro, pois sem o outro não existirá convivência humana, trabalho e riqueza, cultura, como haverá amor e alegria. 


\section{Por uma Psicologia de promoção da vida}

Os hospitais na pandemia constituem em espaços de separação e desaparecimento, assim como os cemitérios com as valas coletivas comuns de hoje são os novos campus de refugiados dos que não escaparam da pandemia, dos que com a vida denunciam a ausência da promoção da saúde, um lugar onde os vestígios se apagam retirando a identidade humana (VILELA, 2000).

O SUS foi fruto de lutas, dos movimentos populares de saúde e do movimento sanitarista. Hoje é o SUS que salva vidas humanas.

Lembremos Marcus Vinícius, um psicólogo social assassinado por viver coerente com a luta pela igualdade de todos: "O Brasil tem um problema radical profundo, e se não somos capazes de refletir sobre isso, dificilmente poderemos superar. Por isso colocamos o tema da desigualdade social" ${ }^{2}$. A desigualdade social determina o futuro das pessoas, assim como a pandemia democratiza a dor a todos os segmentos sociais. Famílias são humilhadas ao chegarem à porta de um hospital sem poder receber socorro emergencial, como em uma guerra. Famílias dormem a porta de hospitais sem informação do estado de saúde dos familiares afetados pelo coronavirus. São corpus violados por um vírus que desafia a ciência, as grandes potências econômicas e politicas, "parece que quase ninguém escapa dele".

O medo, que mobiliza a pandemia, é de não conseguirmos como ser humano cuidar de si e do outro. Os inimigos de hoje não são os jovens estudantes loucos por liberdade, somos nós mesmos que colocamos a economia acima da vida. Por isso, essa crise movida pela pandemia é uma crise de humanidade.

Como interferir com os coletivos, a partir da experiência intersubjetiva, em tempos de pandemia? Como pensar a promoção da saúde quando a comunidade se vê diante do risco maior da vida humana. Erich Fromm, em O Medo à liberdade, escrito em 1941, trata do perigo de as sociedades democráticas de serem transformadas em sociedades autoritárias, a partir da interligação de fatores psicológicos, econômicos, culturais e ideológicos.

Fomos compelidos a reconhecer que milhões de alemães estavam dispostos a abrir mão de sua liberdade, do mesmo modo que seus pais estavam dispostos a lutar por ela; que em vez de desejarem a liberdade eles buscavam meios de fugir dela; que outros milhões eram indiferentes e não julgavam valer a pena lutar e morrer pela liberdade (FROM, 1970, p.14).

Não é a toa que setores fascistas nesse momento aproveitam o caos e a insegurança humana coletiva para tentar desmoralizar as instituições pú-

2 Disponível em: https://www.youtube.com/watch?v=pPot059qnpw. Acesso em: 25 abr. 2020. 
blicas buscando transformar pela força, o regime democrático em ditadura, chegando ao ponto de invadir hospitais desrespeitando doentes e equipe de saúde. A lição dos tempos de totalitarismo e ditaduras é de que os tiranos não dormem nunca, como afirma Ana Maria Machado (1982), estão sempre rondando ao redor da cidade procurando uma oportunidade para voltar a tiranizar. Nas sombras da noite eles vigiam e armam esquemas de poder. Cabe a sociedade aprender com os direitos humanos que nem podemos esquecer as lições da escravidão, do holocausto, das ditaduras e da pandemia, mas que precisamos resistir todas as formas de opressão e violência (ADORNO, 2003).

Resistir com as células, resistir com a força mental, resistir com a solidariedade, resistir com o afeto pode clarificar o entendimento dos desafios sem com isso, deixar de defender a liberdade, a vida, a igualdade e a solidariedade. Benevides (1997, p. 12) afirma para essa direção, quando afirma que a educação para a cidadania e os direitos humanos decorre de uma opção radical pelos valores republicanos e democráticos. Cada cidadão (ã) precisa se "reconhecer como sujeito de direitos e deveres, mas também sujeito criador de direitos".

Sem o Pantanal, a Amazônia e até o Deserto do Atacama não haverá memória, não haverá a permanência do homem e dos seres vivos. A pandemia traduz a linguagem dos direitos humanos, ao alertar que sem a natureza e os defensores da floresta o pulmão da terra não poderá respirar, assim como, sem o trabalhador não haverá produção e lucro.

Da dor brotam formas ativas de solidariedade com os diferentes profissionais que estão na porta da entrada da pandemia. A pandemia ensina todos os dias o valor da solidariedade ativa dos profissionais de saúde, de assistência social, de segurança e dos trabalhadores de cemitérios. Essas pessoas e profissionais em tempos de pandemia representam os direitos humanos, porque são capazes de colocar a vida pessoal em defesa da vida coletiva. São assim, também, os povos indígenas, que desde os tempos pré-colombianos lutam pela defesa das aguas e florestas sem a lógica da dominação e do lucro. Convivendo em Pandemia pudemos resinificar nossas subjetividades, talvez, agora, mas cuidadosos, já que experienciamos o valor da saúde psíquica e biológica. Aprendemos também o quanto à ciência pode ser relevante para preservar a liberdade e a vida dos seres vivos. Mas da solidariedade ouvimos os gritos de dor e agimos em direção, aprendendo direitos humanos através de redes e comitês de solidariedade em escolas e universidade, na internet, no mundo do trabalho e na defesa dos profissionais de saúde. 


\section{Referências}

ADORNO, Theodor W. Educação e emancipação. 3. ed. São Paulo: Paz e Terra, 2003.

AGUIRRE, Luis Pérez. Depoimento dos convidados estrangeiros no Congresso Brasileiro de Educação em Direitos Humanos. Jornal da Rede Brasileira de Educação em Direitos Humanos (RBEDH), São Paulo, n. 2, set. p. 7, 1997.

BENEVIDES, Maria Victoria. Educação, democracia e direitos humanos. Jornal da Rede Brasileira de Educação em Direitos Humanos (RBEDH), São Paulo, n. 1, mai., p. 12, 1997.

FOUCAULT, Michel. O poder e a norma. In: KATZ, Samuel (org.). Psicanálise, poder e desejo. Rio de Janeiro: Coleção Ibrapsi, 1979.

FROM, Erich. L O medo à liberdade. Rio de Janeiro: Zahar, 1970.

GONZÁLEZ-REY, Fernando. Sujeito e subjetividade. São Paulo: Thomson, 2005.

MACHADO, Ana Maria. Era uma vez um tirano. Rio de Janeiro: Salamandra, 1982.

SILVA, Marcus Vinicius de Oliveira. CREPOP História, avanços e desafios da psicologia nas politicas públicas. Disponível em: https://www.youtube.com/ watch?v=pPot059qnpw^. Acesso em: 25 abr. 2020.

VILELA, Eugénia. Os arquivos da dor. In: CARVALHO, Adalberto Dias de (org.). A educação e os limites dos direitos humanos. Porto: Porto Ed., 2000, p. 125137. 
